\title{
Uso, Estudo e a Cultura dos Métodos Bibliométricos
}

\author{
Use, Study and Culture of Bibliometric Methods
}

Gildenir Carolino Satos ${ }^{1}$, Danielle Thiago Ferreira ${ }^{1}$

${ }^{1}$ Universidade Estadual de Campinas

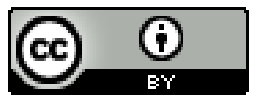

Prezados Leitores,

Iniciamos o ano de 2017, comunicando o lançamento de mais um volume, ou seja, contendo o fascículo 15 da edição de janeiro a abril de 2017.

Sentimo-nos agradecidos por ter recebido excelentes trabalhos para compor essa temática que foca cada vez mais a tendência das métricas nos serviços bibliotecários e demais áreas do conhecimento correlacionadas com a Biblioteconomia e Ciência da Informação.

A novidade a partir desse volume é o novo layout da RDBCI que ganha maior alinhamento no design, mais clean facilitando melhor leitura de seu conteúdo e acompanhando a tendência das publicações científicas.

Por ser de fluxo contínuo, a Revista tem como tradição reunir os trabalhos e destacar uma temática em função dos artigos recebidos. Nessa edição, a temática tem como propósito o "Uso, estudo e a cultura dos métodos bibliométricos".

Os métodos bibliométricos, ou precisamente denominado bibliometria, é um "campo das áreas da Biblioteconomia e da Ciência da Informação que aplica métodos estatísticos e matemáticos para analisar e construir indicadores sobre a dinâmica e evolução da informação científica e tecnológica de determinadas disciplinas"1. Como bem visto, muitas áreas utilizam esses métodos bibliométricos para comprovarem a eficácia das suas pesquisas estatisticamente, e isso tem se tornado cada vez mais frequente.

A bibliometria possui também amplas relações com as áreas de cientometria, infometria, webometria, patentometria, altmetria dentre outros. Essa última área, tem apresentado grande impacto e divulgação nas mídias sociais quando falamos de forma mais popular em relação a sua nomenclatura, ou seja, métricas alternativas.

Como enfatiza Ernesto Spinak, colaborador do SciELO, engenheiro de sistemas e licenciado em Biblioteconomia, "as altmetrias são ferramentas em fase experimental que tem, todavia, dois temas a resolver. O primeiro é técnico, e se refere à recopilação de dados com melhor

\footnotetext{
${ }^{1}$ Bibliometria. In: WIKIPEDIA, 2016. Disponível em: <https://pt.wikipedia.org/wiki/Bibliometria $>$. Acesso em: 31 jan. 2017.

\begin{tabular}{l|l|l|l|l|l}
\hline (C) RDBCI: Rev. Digit. Bibliotecon. Cienc. Inf. & Campinas, SP & v.15 & n.1 & p. 1-6 & jan./abr. 2017 \\
\hline
\end{tabular}
}


cobertura, em diversos idiomas, e poder resolver ambiguidades. Isso poderá ser obtido, uma vez que existem padrões internacionais aceitos, da mesma maneira que se obtiveram em outras métricas como Counter, para a medição do uso de recursos eletrônicos."

Dessa forma, podemos verificar que a RDBCI traz todas essas vertentes que os métodos bibliométricos apontam para os estudos e pesquisas que venham fazer parte dessas ricas e poderosas ferramentas de análises.

Além da temática em voga, outros trabalhos abordam temas mais específicos e relevantes para área que poderão ser degustados nesse fascículo. Outro enfoque que devemos destacar, antes de iniciarmos as resenhas sobre os trabalhos dessa edição, é que os três melhores trabalhos premiados durante o $18^{\circ}$ Seminário Nacional de Bibliotecas Universitárias (SNBU), ocorrido em outubro de 2016 em Manaus, foram convidados a serem publicados neste fascículo. Os trabalhos, como de praxe, foram avaliados pela Comissão Científica do evento, e também avaliados por pareceristas da Revista, que destacaram os devidos méritos para serem publicados como trabalhos científicos. Nesse viés foram classificados pela Revista, como trabalhos apresentados em eventos, encaixando-se na seção Comunicações.

Face a essa determinativa em relação aos indicadores bibliométricos, a partir do momento em que iniciamos na Revista a utilização da Publicação Avançada, ou mais conhecida como Ahead of Print, a RDBCI tem alcançado altos índices na constituição de seus dados altmétricos, justamente por estar utilizando desde 2015, o plugin PLOS $\mathrm{ALM}^{3}$ na plataforma $O J S$, evitando assim que, o artigo esteja parado até a sua publicação, após avaliado.

Teremos nessa edição 14 trabalhos, sendo 7 trabalhos na seção Artigos; 4 trabalhos na seção Artigos de Pesquisa e 3 trabalhos na seção Comunicações.

Abrindo a seção Artigos, as autoras Juliana Soares de Souza, Maria Zanin (ambas da Universidade Federa de São Carlos) trazem o trabalho intitulado "Catadores e movimento social: uma pesquisa bibliométrica" que tem como objetivo demonstrar a importância do tema estudado, analisando pesquisas que empregaram os termos "Movimento Social" e "Catadores de Materiais Recicláveis" e seus respectivos correlatos, na base de dados CAPES. A pesquisa bibliométrica apontou para as peculiares das publicações e permitiu uma análise pormenorizada da justificativa sobre a importância da temática "movimento social de catadores de materiais recicláveis no campo científico", conceituado no trabalho como ferramenta de divulgação e reivindicação de direitos sociais, por ora renegados pela sociedade brasileira, cuja desigualdade social alimenta a exclusão.

\footnotetext{
2 SPINAK, E. O que podem nos fornecer as “métricas alternativas” ou altmetrias. SciELO em Perspectiva, 2014. Disponível em:<http://blog.scielo.org/blog/2014/08/07/o-que-podem-nos-fornecer-as-metricas-alternativasou-altmetrias/>. Acesso em: 31 já. 2017.

${ }^{3}$ Article-Level Metrics. Disponível em: <http://pkp-alm.lib.sfu.ca/>. Acesso em: 31 jan. 2017.
} 
O segundo artigo sobre a "Produção técnico-científica dos bibliotecários do instituto federal de São Paulo: um estudo neobibliométrico", de Cintia Almeida da Silva Santos e Fernanda Rodrigues Pontes (ambas do Instituto Federal de Educação, Ciência e Tecnologia de São Paulo) tem como objetivo mapear e analisar a produção técnico-científica dos bibliotecáriosdocumentalistas das bibliotecas do Instituto Federal de Educação, Ciência e Tecnologia de São Paulo (IFSP), o que favoreceu a busca de soluções para os problemas enfrentados pelos profissionais, além de evidenciar seus câmpus e suas bibliotecas no cenário técnico-científico nacional e internacional.

No terceiro artigo sobre "Internacionalização da produção científica do Brasil em física de altas energias (1983-2013)" os autores Gonzalo Rubén Alvarez, Sônia Elisa Caregnato (ambos da Universidade Federal do Rio Grande do Sul), realizaram um estudo bibliométrico para analisarem as dimensões da internacionalização da produção científica brasileira em Física de Altas Energias (FAE) a partir dos artigos publicados em revistas indexadas pela Web of Science (WoS) no período de 1983-2013.

Em “Gestão da informação para a tomada de decisão em uma instituição de ensino superior privada", Gleiciane Rosa da Silva Silva (Universidade de Brasília), analisou a gestão da informação na tomada de decisão na Faculdades Integradas da União Educacional do Planalto Central (FACIPLAC/DF).

Jorge Santa Anna (Universidade Federal do Espírito Santo), traz com o trabalho "A cultura como elemento agregador para as unidades de informação: pluralizando manifestações culturais" reflexões acerca da relação existente entre a cultura com as principais unidades de informação, aqui representadas pelas bibliotecas, arquivos e museus. $\mathrm{O}$ autor conceitua cultura no âmbito social; discorre o papel das bibliotecas, dos arquivos e dos museus quanto à cultura no decurso da história; apresenta a função social relacionada à cultura inerente no fazer dos profissionais da informação, além de expor a participação e valorização do poder público quanto aos investimentos realizados nessas instituições, considerando aspectos culturais.

No sexto artigo "Desenvolvimento das universitárias na Idade Média até à Modernidade" de autoria de Fabiene Castelo Branco Diógenes (Instituto Brasileiro de Informação em Ciência e Tecnologia) e Murilo Bastos da Cunha (Universidade de Brasília), analisam, por meio de uma abordagem da pesquisa bibliográfica e descritiva, a origem das universidades, suas lutas pela autonomia, organização das estruturas administrativa e curricular e relata a existência das bibliotecas ligadas às universidades, desde a Idade Média até a Modernidade.

"Análise do padrão RDA: um estudo aplicado em teses e dissertações em literatura e cinema", último artigo dessa seção, Raquel Bernadete Machado e Ana Maria Pereira (ambas da (Universidade Federal de Santa Catarina), tiveram como objetivo analisar como os registros bibliográficos de teses e dissertações das áreas de literatura e cinema serão modificados com os padrões do código Resource Description and Access (RDA) - padrão de 
catalogação desenvolvido para substituir o Código de Catalogação Anglo-Americano, segunda edição (AACR2) - com a finalidade de melhorar a recuperação da informação.

$\mathrm{Na}$ seção Artigos de Pesquisa, Juliana Ravaschio Franco de Camargo (Universidade Estadual de Campinas) e Maria Cristina Piumbato Innocentini Hayashi (Universidade Federal de São Carlos) apresentam o trabalho "Co-autoria e participação feminina em periódicos brasileiros da área de cirurgia: estudo bibliomátrico". Este artigo expõe os resultados de uma pesquisa que teve como objetivo identificar e analisar a produção científica brasileira em cirurgia através de artigos científicos publicados no período de 2010 a 2014 em quatro periódicos: Acta Cirúrgica Brasileira (ACB), Arquivos Brasileiros de Cirurgia Digestiva (ABCD), Revista Brasileira de Cirurgia Cardiovascular (RBCCV) e Revista do Colégio Brasileiro de Cirurgiões (RCBC).

Dando continuidade, o próximo trabalho intitulado "A construção de um programa de letramento informacional e arte educação", de Alexandra César Zinn e Kelley Cristine Gonçalves Dias Gasque (ambos da Universidade de Brasília) analisam a interligação dos conteúdos de letramento informacional aos conteúdos de Arte no ensino médio por meio de pesquisa descritiva realizada com arte-educadores da secretaria de educação do Distrito Federal, regional de ensino do Recanto das Emas.

No terceiro trabalho sobre "Marketing digital e de relacionamento: avaliação de um sistema de informação digital usando uma integração da TAM, TTF e modelos KMV”, Plínio Rafael Reis Monteiro (Universidade Federal de Minas Gerais) e Raquel Vaz de Mello Strambi Zeringota (Universidade FUMEC) buscaram verificar nesse estudo como a interação tecnológica do portal de uma IES afeta atitudes e intenções comportamentais dos discentes, em que o estudo, a partir de um survey concebido pelos modelos TAM, TTF e KMV, evidenciou que as características e a adequação da tecnologia influenciam na utilidade percebida no portal e nas atitudes moderadoras de intenções comportamentais para a instituição estudada.

No quarto e último da seção Artigo de Pesquisa, trazemos o trabalho intitulado "Checklist de acessibilidade em ambientes informacionais na Web", de autoria de Christiane Gomes dos Santos, Sueny Gomes Léda Araújo, Marckson Roberto Ferreira de Sousa, Wagner Junqueira de Araújo (todos da Universidade Federal da Paraíba), que abordam os processos de busca, navegação e recuperação da informação pela pessoa com cegueira em ambiente web, focalizando no conhecimento das áreas de recuperação e arquitetura da informação, o entendimento das estratégias utilizadas por essas pessoas para o acesso à informação na web. Além disso, a pesquisa tem como objetivo propor a construção de um instrumento de verificação de acessibilidade, checklist, a ser utilizado para análise do comportamento da pessoa com cegueira em ações de busca, navegação e recuperação em sites e páginas. 
Na seção Comunicações, apresentamos os trabalhos premiados no $18^{\circ}$ Seminário Nacional de Bibliotecas Universitárias (SNBU), e que foram também avaliados pelo Comitê de Pareceristas da Revista.

O primeiro trabalho intitulado "O uso de aplicativos de saúde para dispositivos móveis como fontes de informação e educação em saúde" de Ana Rachel Fonseca de Oliveira (Universidade do Estado do Rio de Janeiro) e Maria Simone de Menezes Alencar (Universidade Federal do Estado do Rio de Janeiro) propõem que a biblioteca universitária seja utilizada como um espaço de ensino e incentivo ao uso de dispositivos móveis como ferramentas educativas, visto que o uso em massa de tablets e especialmente de smartphones reforçam o conceito de aprendizagem móvel e ampliam suas possíveis funções dentro do espaço físico da biblioteca.

Na segunda Comunicação, Vítor Vasata Macchi Silva, Andreia Petró da Rosa, Ana Cláudia da Costa Leite, Rodrigo Silva Caxias de Sousa Universidade Federal do Rio Grande do Sul), trazem o trabalho sobre a "Identificação de requisitos de qualidades demandados por usuários de bibliotecas universitárias” que teve como objetivo identificar o perfil dos usuários que frequentam essa Biblioteca e, também, os requisitos que esses mais valorizam em unidades de informação. Os autores também propõem melhorias relacionadas aos requisitos mais valorizados pelos usuários da Biblioteca Central de uma Universidade Federal identificados a partir de um estudo de usuários. Apontam que o atendimento das propostas listadas, tais como infraestrutura, salas fechadas para estudo em grupo, rede wi-fi podem contribuir para a melhoria da percepção dos usuários com relação aos serviços oferecidos pela Biblioteca.

E, finalmente por último, Maira Nani França, Kelma Patrícia de Souza e Patrícia de Oliveira Portela (Universidade Federal de Uberlândia), contribuem com o trabalho "Quanto vale a informação? Calculando o valor econômico de serviços de uma biblioteca", tendo como objetivo atribuir valor econômico aos serviços prestados por uma biblioteca universitária brasileira, a fim de desenvolver uma ferramenta que venha auxiliar os gestores nos processos de tomada de decisão e avaliação das unidades informacionais visando a garantia da qualidade dos serviços prestados.

Vale a pena lembrar que, todos os trabalhos apresentam sua versão na língua inglesa - um dos fatores determinantes dessa publicação, objetivando a internacionalização deste periódico desde final de 2015.

Então, aproveitem, naveguem e leiam os trabalhos dessa edição que acaba de ser lançada. Uma excelente leitura e um ótimo 2017 para todos.

Correspondência

Editores da RDBCl

Universidade Estadual de Campinas - Sistema de Bibliotecas

Bibioteca Central César Lattes $-1^{\circ}$ piso

Campinas, SP

Tel: 19-3521-6729

Email: rdbci@unicamp.br
Gildenir Carolino Santos

Danielle Thiago Ferreira

Editores Científicos da RDBCI

Janeiro/2017

(C) RDBCI: Rev. Digit. Bibliotecon. Cienc. Inf.

\begin{tabular}{l|l} 
Campinas, SP & v.15 \\
\hline
\end{tabular}

n.1

p. 1-6

jan./abr. 2017 


\section{REFERÊNCIAS}

Bibliometria. In: WIKIPEDIA, 2016. Disponível em: <https://pt.wikipedia.org/ wiki/Bibliometria>. Acesso em: 31 jan. 2017.

SPINAK, E. O que podem nos fornecer as "métricas alternativas" ou altmetrias [online]. SciELO em Perspectiva, 2014. Disponível em: <http://blog.scielo.org/blog/2014/08/07/oque-podem-nos-fornecer-as-metricas-alternativas-ou-altmetrias/>. Acesso em: 31 já. 2017.

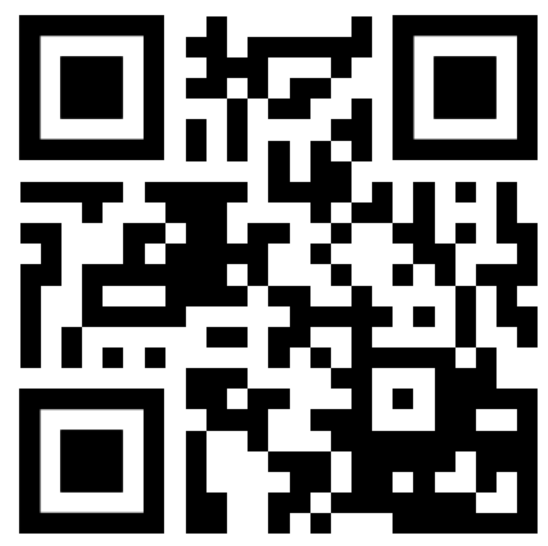

